\title{
On-line Modules for Energy Balance Courses: Effectiveness Study
}

\author{
Konstantinos Apostolou ${ }^{1}$ \\ Stephanie Bertolo ${ }^{2}$ \\ ${ }^{1} \mathrm{~W}$ Booth School of Engineering Practice and Technology \\ ${ }^{2}$ Arts and Science Program \\ McMaster University \\ Hamilton, ON \\ Corresponding Author: apostol@mcmaster.ca
}

\begin{abstract}
The effectiveness of a series of online quizzes use to "blend" a traditional face-to-face fundamental chemical engineering course is examined. Six quizzes were offered to the students: four counting for grade and two optional, followed by in-class quizzes. All quizzes focused on foundational course concepts. Students were also asked to complete two surveys: one at the beginning of the course to examine their previous experiences with online homework and testing and one at the end of the course to investigate their perceptions about the value and the logistics of this course's quizzes.

Results indicate that students use multiple attempts on the quizzes counting for grade, but do not try the optional quizzes. That happens even though they value the quizzes highly in terms of helping them keep on track with the course material, build problem-solving skills, and improve their critical thinking. Evidence indicates that students favour having similar quizzes in other fundamental engineering courses.
\end{abstract}

Keywords: Chemical engineering, mass and energy balances, online homework, quizzes, survey, student perceptions, quiz effectiveness

\section{INTRODUCTION}

There is no dispute that any form of active learning improves student learning and knowledge retention [2, 5]. The challenge, though, is that most forms of active learning require the presence of students in the classhence, cannot reach students not attending lectures - and do not promote, or enforce, out-of-class practice and learning. To address these issues and to appeal to a primarily millennial student body-technologically savvy with busy lifestyles and competing demandsmany educators have augmented traditional face-to-face engineering lectures with online components: podcasts, homework, or quizzes resulting to some form of blended learning. The results of such approaches are usually encouraging with increased student performance, participation, and learning.

Students, in general, appreciate the immediate feedback provided through electronic in-class or online quizzing avenues [3, 9] and instructors feel that students are better prepared for in-class reflections and discussions when they have taken an online quiz prior to the class [10]. While all researchers indicate that the addition of online modules results to improve learning outcomes compared with traditional face-to-face instruction [4, 5, 7, 9, 11], some [12] point out that weaker students are the ones mostly benefiting from online quizzes. Surprisingly, though, these students are the ones that primarily complain about the extra work load resulting from quizzes [12]. Still, the required work load associated with acquiring certain learning is significantly reduced when online quizzes are used as a learning tool [6]. Clearly, online homework is overwhelmingly benefiting learning, but its effectiveness depends on how it is designed, as most aforementioned researchers indicate. In addition, Liberatore [8] shows that the benefit is maximized when personalized online homework problems are used.

The authors were motivated by these studies and by preliminary results obtained by one of them [1] and decided to perform an in-depth study on the effectiveness of online quizzes for a vapour-liquid equilibrium and energy balance course. Six quizzes were used in the course: four mandatory-i.e. counting for grade - and two optional but followed by in-class quizzes on relevant material. The students' performance on these was recorded. In addition, two surveys were provided to students: one at the beginning of the semester to investigate their attitude towards online quizzes in general and one at the end of the course to examine the degree of learning value they assign to the specific course quizzes. This research protocol has been clear by our institution's research ethics board. 


\section{STUDY SET-UP}

\subsection{The Course and the Students}

The course and the group of students were described in detail in [1]. In short, it is a mandatory second year course on vapour-liquid equilibrium and energy balances. It is a typical chemical engineering course, delivered to a cohort of students studying process automation; hence, it is considered by many students as a course outside their "core" competencies. The course has a lecture component - three hours per week - worth $75 \%$ of the grade and a weekly lab component - three hours per week in unit operation labs - worth $25 \%$. The course has been taught by the first author for the past seven years. The cohort in Winter 2017, on which this study focuses was fifty five students.

\subsection{Online quizzes.}

Starting in 2015, online quizzes have been implemented for augmenting the in-class lecture and any active-learning components during it. The rationale behind the online quizzes is to first motivate students to work on course material on a regular basis and to second help them build strong foundations on critical course concepts. To that end, quizzes are always focused on material that has been taught in class and consider fundamental - to the instructor's view-concepts. Over the years, the material covered through these online quizzes has been expanding, as has the pool of questions. In Winter 2017, there were six quizzes:

- Quiz 1 on vapour pressure calculation and vapourliquid equilibrium for multi-component systems.

- Quiz 2 on the ternary diagram for liquid/liquid equilibrium and solubility calculations for solid/liquid equilibrium.

- Quiz 3 on using the steam tables.

- Quiz 4 on energy balances using the steam tables

- Quiz 5 on calculating specific heat capacity values from Tables and on using these values in enthalpy change calculations.

- Quiz 6 on the Hess law and mass balances on reactive systems.

In each quiz, students had to answer between eight and twelve questions. Questions were randomly selected from a (limited) pool of relevant questions and calculation questions were using random numbers. Students had three attempts on each quiz, with the best one counting for grade. After each attempt, students were shown all questions with their score on them and were also given the correct answer for calculation only questions. This was done to somewhat preserve the integrity of multiple-choice, multi-select, on matching questions which have set answers, whereas revealing the answer on randomly-generated calculation questions would help students track their mistakes and reflect on them. All quizzes were delivered through McMaster's online learning management systems (D2L).

Out of the six quizzes, quizzes number four and five were "optional", serving as practice for following inclass paper-based problem-solving quizzes. The rest of the quizzes were "mandatory", counting towards the final grade. Overall, the best five of the six-four online and two in-class-quiz grades were kept and they counted for a total $15 \%$ of the course grade.

\subsection{Student Surveys.}

In order to obtain more in-depth information about the effects of the quizzes on students' learning, students were asked to voluntarily complete two surveys. The first survey, available at the beginning of the term, consisted of ten questions on students' expectations from the online quizzes. Students should answer based on their previous experiences with such learning modules. The second survey, available during the final two weeks of the term, consisted of twenty six questions-primarily on the Likert scale-about students' experiences with the quizzes on this particular course.

Both surveys were conducted online through LimeSurvey and only the second author, being free of any conflict of interest with the students, had access to the survey responses. She was also responsible of removing any personal identifiers from the data before sharing them with the second author and course instructor. To further protect students, this data sharing occurred after the final course grades had been submitted. Unfortunately, due to anonymity concerns, responses on the two surveys could not be connected to individual participants - i.e. it was not possible to relate responses to the second survey to the same student's responses on the first survey.

During the second survey, students were also asked to voluntarily grant the authors permission to:

- Connect their quiz grades to the course performance and/or

- Connect their quiz grades and course performance to their performance on previous courses within the institution.

A focus groups was also planned but did not take place because of limited student interest. 


\section{RESULTS and DISCUSSION}

\subsection{Quiz data}

The quiz results overwhelmingly support the evidence presented in [1].

- Students perform the mandatory quizzes, but do not value the optional quizzes: 101 versus 11.5 attempts on average.

- Students perform quizzes primarily on the last day: on average, $68 \%$ of the quiz attempts were performed on the day the quiz would close.

- In general, the quiz average score increased between the first and second attempt, but dropped in the third attempt: primarily because students, discouraged from the possibly new to them questions they got on the third attempt, abandoned it.

- A few students revisited the quizzes before the final exam as a study tool: ten attempts in total within the final exams period.

- On average, fifty out of the fifty five students attempted the quizzes: most of them, obviously, value the grade connected to quizzes and, possibly, the practice obtained through the quizzes.

\subsection{Previous experiences survey responses.}

The first survey focused on students' previous experiences with online quizzes and/or online homework. Eleven students took the survey and ten of them had previous experiences with online quizzes in other courses. In general, their experiences were positive, with $73 \%$ believing that quizzes had a positive or strong positive impact and only $9 \%$ believe that the quizzes had a negative impact on their course understanding. They overwhelmingly prefer online to in-class quizzes (Fig. 1), but do not necessarily work in groups to complete them (Fig. 2).

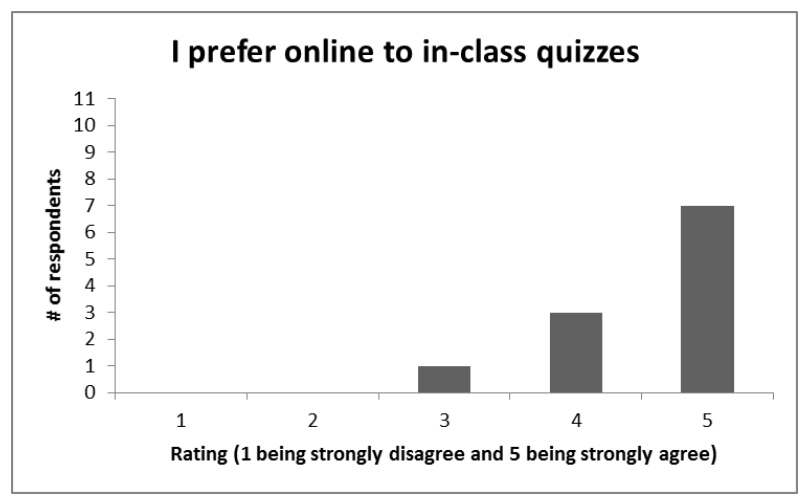

Fig. 1. Online quiz student preference.

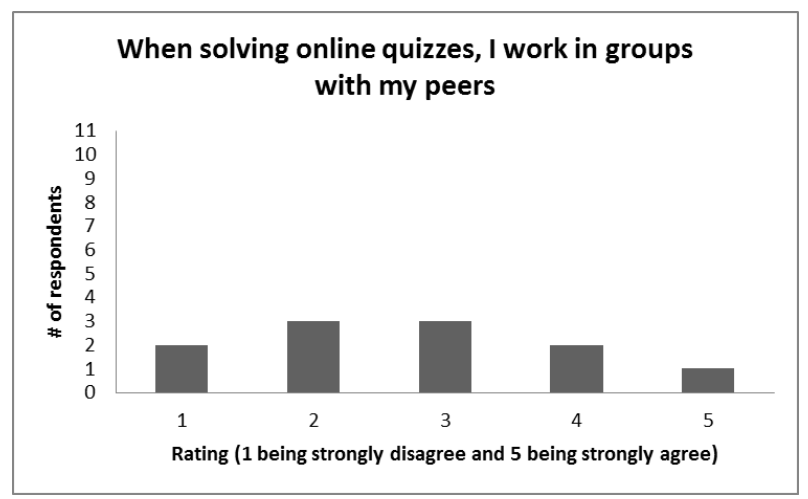

Fig. 2. Quiz completion in groups.

With regards to the type of quizzes and their effect on the course, students believe that low-value quizzes are a good option (Fig. 3) and that quizzes help them keep ontrack with their studying (Fig. 4).

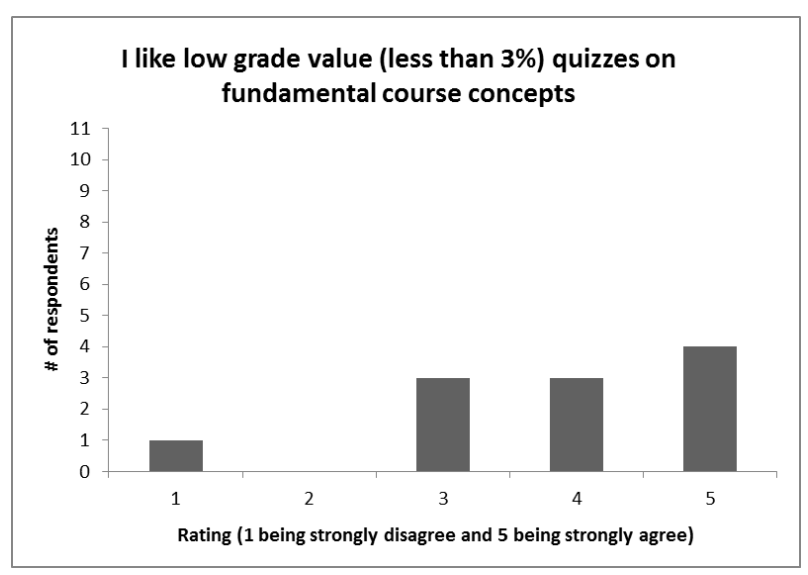

Fig. 3. Quiz completion in groups

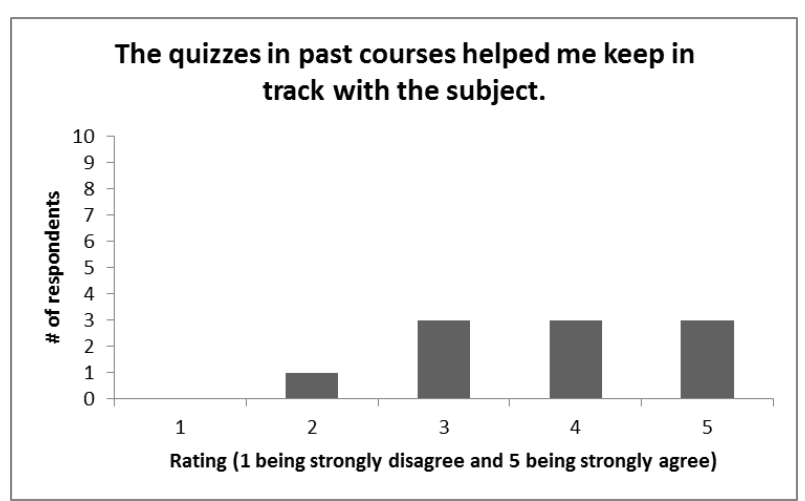

Fig. 4. Quizzes effect on past courses 


\subsection{Course experiences survey responses.}

The second survey, conducted during the final two weeks of classes, focused on students' experiences with the quizzes they had to complete in this course. Fourteen students took the survey, but only nine of them completed it and submitted responses that can be used. All questions were in a Likert scale from 1 (strongly disagree) to 5 (strongly agree) and concerned the quiz logistics, their perceived value as assigned by the students, and their impact on the course. Because of the plethora of questions (twenty six in total), only the average and the standard deviation of the responses in each question are presented here.

Figure 5 shows that students think of quizzes as a good learning tool and did not have any issues with the types of questions and the amount of time allowed for solving them.

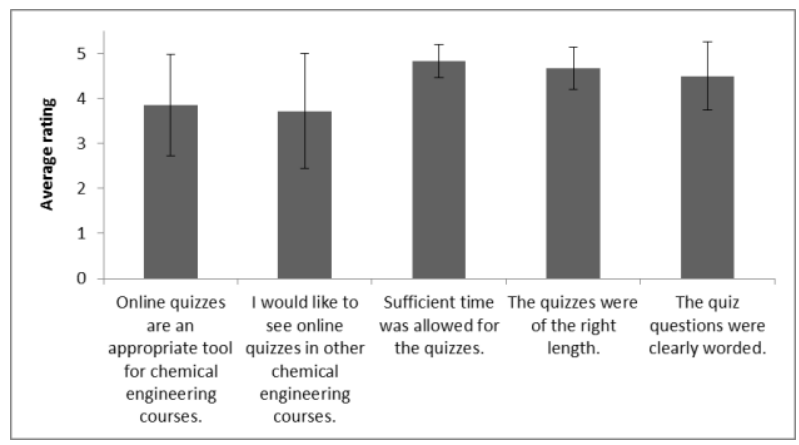

Fig. 5. Length, timing, and appropriateness of quizzes

In addition, as indicated in Fig. 6, they did not find the quizzes to be too challenging-all responders answered that they disagree or are neutral to that question - or significantly time consuming - only one participant agreed that they spent too long each week on this course in general. Still, though, they think the quiz performance is a good reflection of their overall course abilities.

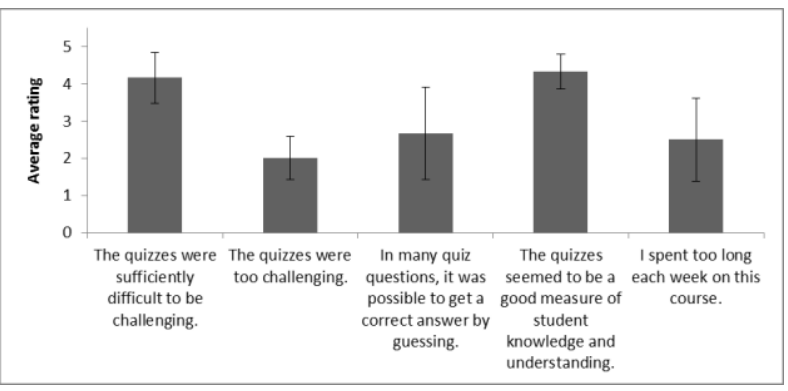

Fig. 6. Quizzes difficulty and learning measure
Overall, students found the quiz load to be not heavy: $85 \%$ disagreed or strongly disagreed with it being heavy, while the remaining $15 \%$ was neutral. With regards to the whole course, most students could "handle the workload of this course": $85 \%$ of the students agreed or strongly agreed with that statement, while $15 \%$ strongly disagreed.

The next group of survey questions were focused on the quizzes effectiveness on the students' learning process. As it can be seen on Fig. 7, students embraced the quizzes as a tool that promoted deeper learning and problem solving: it engaged critical thinking, discussion between peers, and application of knowledge to new situations

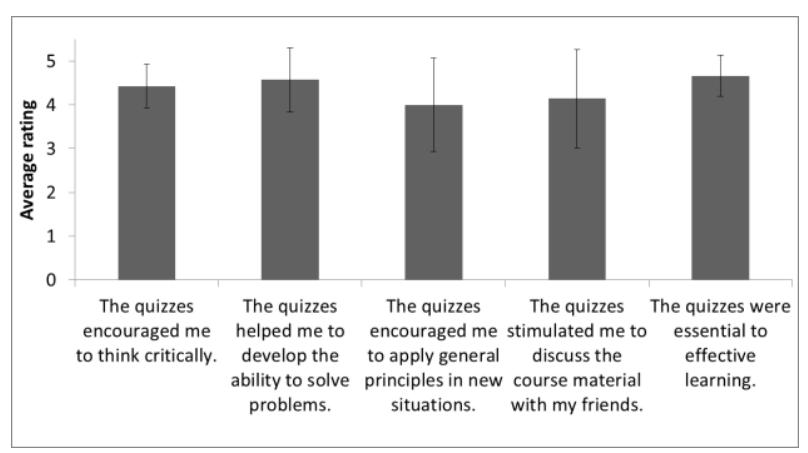

Fig. 7. Quizzes effect on learning

Finally, students were asked to give their overall opinion on the impact the quizzes had on this course. Figure 8 has their responses. Cleary quizzes motived students to keep on track with the course, study harder and helped them understand the course material. Students also show a preference to online quizzes, as also indicated in the first survey, to in-class ones, but are not completely denouncing paper assignments in place of online quizzes.

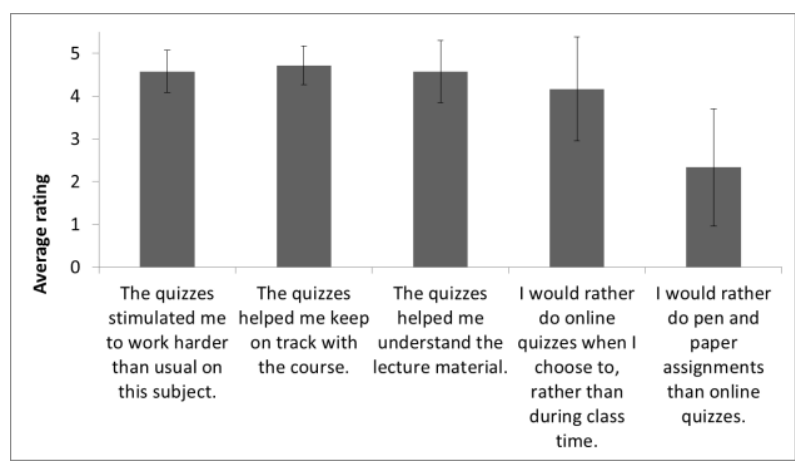

Fig. 8. Quizzes impact on course

On a slightly different question, students were asked if they work in groups in completing the online quizzes. 
Approximately two thirds of the participating students worked on their own, with the remaining one third collaborating in one-to-two quizzes.

The survey also asked for permission to access students' grades in order to relate quiz performance to course performance and overall academic performance. Unfortunately, permission was granted from only four students and the authors decided to not make the comparison, as it would lead to inconclusive results.

\section{CONCLUSION and FUTURE WORK}

It should be noted that the number of responders is very small to draw any solid conclusions from the supplied data. Trends can be identified, but should be considered critically, as there is a concern the data only represent a group of students that are diligent and took the time to respond and not everyone taking the course.

Nevertheless, there is clearly a positive response of students to the quizzes. Students would like to see online rather than in-class quizzes as they believe they help them stay on top of course material, learn concepts, and build problem-solving skills. They also appreciate the fact that they can do them at their own time and not at the pre-set class time. What is really encouraging to the authors is that students' perception of the effectiveness of quizzes in keeping on top of the course material is higher for this course than for previous courses, which is a reflection on the type, level, and difficulty of quiz questions. Still, though, there is room for improvement; for example, many students commented that certain questions could be answered by guessing.

Looking at the overall quiz grades and completion patterns, it is evident that students will not work on optional quizzes. This has to be examined more in the authors' view: since students consider the quizzes an effective learning tool, it was expected that they would try the optional quizzes for practice, something that did not happen. Apparently, students relied on different practice methods, or just on in-class participation for these modules of the course. It would be interesting to assess what these practice avenues are and to exploit them in building multiple and parallel learning opportunities for the students.

Moving ahead, the authors plan on revising the offered quizzes to (i) add multiple variations on problems for providing opportunity for honing problemsolving skills and to (ii) identify and change questions where guessing is possible. On the survey side it is desired to revisit some questions and give students opportunity for providing suggestions for improvement of the online modules. There are also plans to expand the online quiz approach to other fundamental courses taught in the program. The biggest issue, however, is the limited participation of students to the survey and the resulting inability to conduct a focus group and a study on any relationship between the quiz scores and students performance on this course and their academics in general. Evidently, students are reluctant to devote their time for completing surveys, even when these relate to their learning, when not enticed to do so. The authors are investigating whether some surveying components can be part of mandatory, anonymous, course modules or whether prizes can be used to drive students towards survey completion. The possibility of expanding the quiz offering and the whole study to a bigger cohort of students taking a similar course is also examined.

\section{Acknowledgements}

The authors would like to thank the MacPherson Institute at McMaster University for supporting this research through a Research Fellowship to the first author and a Student Partner fellowship to the second author.

\section{References}

[1] Konstantinos Apostolou, "Effectiveness of blended learning for an energy balance course", CEEA Canadian Engineering Education Association Conference (CEEA16), Paper 085, Dalhousie University; June 19 22, 2016.

[2] Lisa G. Ballard and Richard M. Felder, "A studentcentered approach to teaching material and energy balances 2. Course delivery and assessment" Chemical Engineering Education, Vol. 41, pp. 167-176, 2007.

[3] John C. Chen, Dexter C. Whittinghill and Jennifer A. Kadlowec, "Classes That Click: Fast, Rich Feedback to Enhance Student Learning and Satisfaction", Journal of Engineering Education, Vol 99, pp 159-168, 2010

[4] David J. Doorn, Susan Janssen and Maureen O'Brien, "Student Attitudes and Approaches to Online Homework," International Journal for the Scholarship of Teaching and Learning: Vol. 4, No. 1, 2010

[5] Sepideh Faraji, "The enhancement of student's learning in both lower-division and upper-division classes by a quiz-based approach." Chemical Engineering Education, Vol 46, pp. 213-217, 2012

[6] Aaron B. Henson, Kenneth J. Fridley, David G. Pollock and C. Jayne Brahler, "Efficacy of interactive internetbased education in structural timber design", Journal of Engineering Education, Vol. 91, pp. 371-378, 2002.

[7] Daryl Lawton, Nancy Vye, John Bransford, Elizabeth Sanders, Michael Richey, David French, and Rick 
Stephens, "Online learning based on essential concepts and formative assessment", Journal of Engineering Education, Vol. 101, pp. 244-287, 2012

[8] Mathew W. Liberatore, "Improved student achievement using personalized online homework for a course in material and energy balances" Chemical Engineering Education, Vol. 45, pp. 184-100, 2011.

[9] Mathew W. Liberatore, "Active learning and just-intime teaching in a material and energy balances course" Chemical Engineering Education, Vol 47, pp. 154-160, 2013

[10] Michael Marcell, "Effectiveness of Regular Online Quizzing in Increasing Class Participation and
Preparation," International Journal for the Scholarship of Teaching and Learning, Vol. 2, No. 1, 2008

[11] Jimmy Nguyen and Cynthia B. Pascal, "Development of online ultrasound instructional module and comparison to traditional teaching methods", Journal of Engineering Education, Vol. 91, pp. 275-283, 2002.

[12] Eva Sorensen, "Implementation and student perceptions of e-assessment in a chemical engineering module." European Journal of Engineering Education, Vol 38, 172-185, 2013.

[13] Paul S. Steif and Anna Dollár, "Study of usage patterns and learning gains in a web-based interactive static course", Journal of Engineering Education, Vol. 98, pp. 321-333, 2009 